\title{
A Study on Outcome of VVF Repair at Kumudini Women's Medical College Hospital
}

\author{
B Begum ${ }^{1}$, S Khandakar ${ }^{2}$, F Rahman $^{3}$
}

\begin{abstract}
This cross sectional study was carried out on 101 cases of vesico-vaginal fistula who were admitted and operated in Kumudini Women's Medical College Hospital. The aim of the study was to find out the outcome of vesicovaginal fistula repair. A detailed interview was taken from the patients and attendants by using a questionnaire. Necessary information were collected from the patient's record sheets. Small, medium and large sized fistulae were $59.41 \%, 26.73 \%$ and $11.88 \%$ respectively. The result of the study showed that success of fistula repair was $73.27 \%$, though seven cases developed
\end{abstract}

\section{Introduction}

Vesicovaginal fistula (VVF) has a serious impact on a women's physical, mental and social well-being. The world Health organization estimates the prevalence of obstetric fistula is 0.3 percent of all deliveries. In Bangladesh 1.9 percent women are suffering from vesio-vaginal fistula. ${ }^{1} \mathrm{~A}$ study was done by UNFPA and Engender Health, found that the incidence is 1.69 per thousand ever married women . ${ }^{2}$ Among genitourinary fistulas, VVF is the commonest variety. Vesico-vaginal fistula results mainly from obstetrical and gynecological causes. In the developing countries, 80-90 percent VVFs are of obstetrical origin. ${ }^{3}$ Obstetric vesico-vaginal fistulas are caused simply by unrelieved obstructed labor. Prolonged pressure of the baby's head against the back of the pubic bone produces ischemic necrosis of the intervening soft tissue, i.e. some part of the genital tract and bladder. ${ }^{4}$ Ischemic tissue necrosis leads to the development of a genitourinary fistula in the puerperium, usually after 7-10 days. ${ }^{5}$ Other causes include operative injury, traumatic, malignancy, radiation, infection etc. ${ }^{3}$ VVF can be diagnosed by detailed history and clinical examination which includes inspection, palpation, metallic catheterization and dye test. Based on size, VVFs may be tiny (admitting only a small probe), small $(0.5-1.5 \mathrm{~cm})$, medium $(1.5-3 \mathrm{~cm})$, large $(>3 \mathrm{~cm})$ and extensive i.e. involving major loss of bladder and urethra. ${ }^{4}$

\section{Dr. Bilkis Begum, Assistant professor, Department of obstertrics and gynecolgy, Kumudini Women's Medical College, Tangail. \\ 2. Dr. Shahnewaj Khandakar, Assistant professor, Department of obster- trics and gynecolgy, Kumudini Women's Medical College, Tangail. \\ 3. Dr. Florida Rahman, Assistant professor, Department of obstertrics and gynecolgy, Sir Salimullah Medical College, Dhaka.}

\section{Corresponding Author}

Dr. Bilkis Begum, Assistant professor, Department of obstertrics and gynecolgy, Kumudini Women's Medical College, Tangail. stress incontinence. Totally 27 patients were unsuccessfully repaired. Of which 19 (70.37\%) were dropped out, 5(18.52\%) were referred and $3(11.11 \%)$ had operative failure. Post-operative recovery was mostly (87.13\%) uneventful. Urethral leakage $(6.93 \%)$, blocked catheter (2.97\%) and UTI (2.97\%) were the leading complications. To improve the outcome, more training and skill of surgeons, improvised per-operative and post-operative care is necessary. Approaches should be designed to make the incidence of drop out to zero.

Repair of the VVF is still a challenging task for the fistula surgeons world-wide. The outcome of VVF repair depends on many factors like-site, size and number of fistula, urethral length, bladder capacity and amount of scarring etc.

The shorter the urethra, the higher is the chance of stress incontinence. Other associated responsible factors include good pre-operative assessment and care, timing of operation, effective post-operative care and lastly expertise of the type of surgery. Even experts can not cure every case, however. $^{4}$

This study was designed to assess the outcome of VVF repair in Kumudini Women's Medical College Hospital ( KWMCH), Mirzapur, Tangail.

\section{Materials and Methods}

This study was carried out at the fistula ward under the department of obstetric and Gynecology of Kumudini Women's Medical College Hospital (KWMCH), Mirzapur, Tangail. KWMCH is a 750 bedded hospital, situated in rural area about $60 \mathrm{~km}$ away from Dhaka, the capital of Bangladesh. It was a cross sectional study during the period of April 2008 to December 2010. In this period total 101 new patients were admitted and operated in $\mathrm{KWMCH}$. All the patients were enrolled in this study. A data collection sheet was used to collect the information. The information recorded on the sheet were based on detailed history taking by interviewing the patients and attendants, proper clinical examination (sometimes examination under anesthesia), type and location of fistula, methods and attempts of repair, post operative complications and result of operations. All the information and data were systematically recorded and were statistically analyzed.

\section{Results}

All the recorded data were analyzed and was shown in the tabulated form. Table 1 shows, out of 101 patients, 60(59.41\%) had small, 27 $(26.73 \%)$ had medium and $12(11.88 \%)$ had large sized fistula. Only $2(1.98 \%)$ had extensive sized fistula. As per location of fistulae, more than half $(57.43 \%)$ were at bladder base. $24.75 \%$ were located at neck and $4.95 \%$ were at juxtra-cervical region. Circumferential fistulae were $5.94 \%$ and $6.93 \%$ were located at vault. 
Table-1: Distribution of patients according to the type and location of fistula. $(n=101)$

\begin{tabular}{|lcc|}
\hline \multicolumn{1}{|c}{ Fistula } & Number of patients & Percentage \\
Type & 60 & 59.41 \\
Small & 27 & 26.73 \\
Medium & 12 & 11.88 \\
Large & 2 & 1.98 \\
Extensive & & \\
Location & 25 & 57.43 \\
Base & 5 & 24.75 \\
Neck & 6 & 4.95 \\
Juxtracervical & 7 & 5.94 \\
Circumferential & & 6.93 \\
Vault & & \\
\hline
\end{tabular}

Most of the fistulas $(98.02 \%)$ were repaired through vaginal route by flap splitting technique. And only $2(1.98 \%)$ were repaired abdominally. ( Transvesical approach) Table-2.

Table-2: Methods of repair of fistula $(n=101)$

\begin{tabular}{|lcc|}
\hline Route of operation & Number of patients & Percentage \\
Vaginal & 99 & 98.02 \\
(Flap splitting technique) & & \\
Abdominal (Transvesical) & 2 & 1.98 \\
Abdomino- Vaginal & 0 & 0.00 \\
\hline
\end{tabular}

According to table -3 , out of 101 patients, 75 ( $74.26 \%$ ) were repaired at 1 st time, $21(20.79 \%)$ were repaired at 2 nd attempt and $2.97 \%$ were at 3 rd attempt. Only 2 ( $1.98 \%)$ repaired at 4 th attempt.

Table-3: Distribution of patients according to attempts of repair $(n=101)$

\begin{tabular}{|rcc|}
\hline Number of attempt & Number of patients & Percentage \\
$1^{\text {st }}$ attempt & 75 & 74.26 \\
$2^{\text {nd }}{ }_{\text {attempt }}$ & 21 & 20.79 \\
$3^{\text {rd }}$ attempt & 3 & 2.97 \\
$4^{\text {th }}$ attempt & 2 & 1.98 \\
\hline
\end{tabular}

Outcome of 101 patients. 74 (73.17\%) were repaired successfully. The rate of unsuccessful operation is $26.73 \%$ ( Table 04).

Table-4: Outcome of VVF repair $(n=101)$

\begin{tabular}{|rcc|}
\hline Outcome & Number of patients & percentage \\
Successful & 74 & 73.27 \\
Unsuccessful & 27 & 26.73 \\
\hline
\end{tabular}

The causes of unsuccessful VVf repair are shown in Table-5. Out of 27 unsuccessful repair, drop out were 19 (70.37\%), referred to higher centre were $5(18.52 \%)$ and true operative failure were $3(11.11 \%)$.
Table -5: Causes of unsuccessful repair $(n=27)$

\begin{tabular}{|lcc|}
\hline \multicolumn{1}{c}{ Causes } & $\begin{array}{c}\text { Number of } \\
\text { Patients }\end{array}$ & Percentage \\
1.Drop out & 19 & 70.37 \\
a) After $1^{\text {st }}$ attempt & 18 & \\
b) After other attempt & 1 & \\
Referred to higher Centre & 5 & 18.52 \\
3. Operative failure & 3 & 11.11 \\
\hline
\end{tabular}

Table-6 shows out of 74 patients, $75.68 \%$ patients were repaired successfully at 1 st attempt and $20.27 \%$ at 2 nd attempt, $1.35 \%$ and $2.7 \%$ of patients were successfully repaired at $3 \mathrm{rd}$ and 4 th attempt respectively.

Table- 6: Success of repair as per attempt of surgery $(n=27)$

\begin{tabular}{|rcr|}
\hline Number of attempt & Number of patients & Percentage \\
$1^{\text {st }}$ attempt & 56 & 75.68 \\
$2^{\text {nd }}$ attempt & 15 & 20.27 \\
$3^{\text {rd }}$ attempt & 1 & 1.35 \\
$4^{\text {th }}$ attempt & 2 & 2.70 \\
\hline
\end{tabular}

Table-7 shows that out of 74 successfully repaired patients, $90.54 \%$ were really dry i, e no dribbling of urine detected. Rest $9.46 \%$ had incontinence.

Table-7: Functional outcome of successfully repaired patients $(n=74)$

\begin{tabular}{|ccc|}
\hline Functional outcome & Number of patients & Percentage \\
No dribbling & 67 & 90.54 \\
Stress incontinence & 7 & 9.46 \\
1. Mild & 5 & \\
2. Severe & 2 & \\
\hline
\end{tabular}

Table- 8 shows recovery of most of the patients $(87.13 \%)$ were uneventful. Urethral leakage (4.95\%) and blocked catheter $(2.97 \%)$ and UTI $(2.97 \%)$ were the leading complications. Acute renal failure $(0.99 \%)$ and post-operative psychosis $(0.99 \%)$ were also observed.

Table-8: Post-operative complications ( Immediate and Early) $(n=101)$

\begin{tabular}{|lcc|}
\hline \multicolumn{1}{|c}{ Complication } & $\begin{array}{c}\text { Number of } \\
\text { Patients }\end{array}$ & Percentage \\
Acute renal failure & 1 & 0.99 \\
Blocked catheter & 3 & 2.97 \\
Urethral leakage & 5 & 4.95 \\
Urinary tract infection (UTI) & 3 & 2.97 \\
Post-operative psychosis & 1 & 0.99 \\
No complication & 88 & 87.13 \\
\hline
\end{tabular}

\section{Discussion:}

In this study, 101 vesico-vaginal fistula cases were included. Out of these, $59.41 \%$ fistulae were small in size and $12 \%$ 
were large in size. This findings are almost similar to a study carried out at Dhaka Medical College Hospital (DMCH) in 1998 by Akturennassa. ${ }^{6}$ She found the percentage of small sized fistula was $62 \%$. But present finding varies from another study carried out at $\mathrm{DMCH}$ over the period from January 2001 to December 2005, done by Homaira. $^{7}$ The decreased number of large sized fistula in rural area is an important indication of improved antenatal, intranatal and postnatal care in Bangladesh. This is due to continuous efforts of government and non-government health service provider. But large sized fistulas were found more in DMCH. DMCH is the highest referral center for VVF patients. Most of the difficult, complicated and large sized fistulas are referred to $\mathrm{DMCH}$. So, in this regard variation of findings between $\mathrm{KWMCH}$ and $\mathrm{DMCH}$ is quite logical and pragmatic. Here almost all the fistulae were repaired vaginally. This findings are similar to the previous findings in Dhaka Medical College Hospital. ${ }^{8}$ Pre dominancy of vaginal route was found also in other countries. ${ }^{9}$

In this study one important finding was the dropout of the patients. After the 1st attempt of repair, 18 patients were dropped out and after consequence attempts another one was dropped out. The causes of dropout were economical insolvency, acceptance of the condition as destiny and there were nobody to help the patients for attending Kumudini Hospital. Five patients were referred to higher centre. These cases were too much complicated and there is no highly experienced fistula surgeon in KWMCH. Outcome of 101 patients. 74 (73.17\%) were repaired successfully.

The rate of unsuccessful operation is 2 Among 101 patients, 74 (73.27\%) were successfully repaired, of which 67 became really dry. This is comparable with the standard outcome of VVF repair. ${ }^{4}$ This finding also shows that in some cases successful closure of fistula may not totally relief the patients from the distressing symptoms of being wet. ${ }^{10}$ Post-operative recovery of most of the patients were uneventful (87.13\%). Urethral leakage ( $6.93 \%)$, blocked catheter $(2.97 \%)$ and UTI $(2.97 \%)$ were the leading complications. One study ${ }^{7}$ showed $78 \%$ patients had no postoperative complications but $20 \%$ suffered from UTI. Probably the high rate of UTI is related to the sterility status of the whole chain and proper post operative care.

\section{Conclusion}

This study has clearly showed the outcome of VVF repair in $\mathrm{KWMCH}$. Here out of 101 patients, 74(73.27\%) were successfully repaired. The causes of unsuccessful repair were drop out, referral and operative failure. More training and skill of surgeons, dedicated per-operative and postoperative care can improve the outcome. To minimize the drop-out cases, multi sectorial approach should be taken.

\section{References}

1. Directorate General of Health Services. Principles and Practices in Management of Female Genital Tract fistula, Dhaka $2008 ; 3: 21$.

2. Directorate General Health Service. Participants Handbook for Doctors on fistula surgery and management, Dhaka $2008 ; 15$.

3. Dutta DC. Textbook of Gynaecology. 5th ed. Calcutta: New Central book Agency. 2008; 402.

4. Hancock B, Browning A. Practical Obstetric Fistula Surgery. The Royal Society of Medicine Press. 2009; ? 10.

5. Kumar P, Malhotra N. Jeffcoate's Principles of Gynaecology. 7th ed. Jaypee Brothers Medical Publishers (P) LTD. $2008 ; 264$.

6. Aktarunnessa Out come of repairs of genitourinary fistula using different modified technique ( dissertation). Bangladesh College of physicians and surgeons. Dhaka 1998.

7. Homaira R, Khatun S. A study on different surgical methods used for repair of vesico0vaginal fistulas in Dhaka Medical College Hospital. J Medical Today. 2010; 22(1) $: 12$.

8. Begum A. Outcome of surgical repair of vesicovaginal fistula. J Dhaka Med Coll 1996; 5:16-20.

9. Kelly J. Vesicovaginal and rectovaginal fistula. J Royal Soc Med 1992;85.

10. Hudson CN. Stechell M. Howkins J. Shaw text book of operative gynaecology. 6th Ed. B.I. Churchill Livingstone PVT LTD 2001; 18:243. 